Journal of Computer Science 6 (11): 1252-1257, 2010

ISSN 1549-3636

(C) 2010 Science Publications

\title{
Network Data Envelopment Analysis Model for Estimating Efficiency and Productivity in Universities
}

\author{
${ }^{1}$ Mohammad Mahallati Rayeni and ${ }^{2}$ Faranak Hosseinzadeh Saljooghi \\ ${ }^{1}$ Department of Management, Institute Technology of Bahonar, Zahedan, Iran \\ ${ }^{2}$ Department of Mathematics, Sistan and Baluchestan University, Zahedan, Iran
}

\begin{abstract}
Problem statement: The aim of this study was to compute disaggregate performance measures of universities. The traditional models for Data Envelopment Analysis (DEA) type performance measurement are based on thinking about production as a "black box". Inputs are transformed in this box into outputs. One of the drawbacks of these models is the neglect of linking activities. Approach: Network DEA models generally consider processed which represent the main components of the system being studied. Most often the processes were executed in parallel and/or in series. Results: With respect to the network DEA approach, we estimated efficiency, the impact of each variable on the efficiency and productivity changes of the universities in Sistan and Baluchestan state (in Iran) in the period 2004-2009, the findings indicated the average technical efficiency in academic year 2008-2009 increase about 15\%. Conclusion: Network Malmquist indexes showed the universities have on average $1.1 \%$, productivity gain. The main factor of the productivity increase is the progress in technical change.
\end{abstract}

Key words: Data envelopment analysis, network DEA, Malmquist productivity, technical efficiency change, frontier shift

\section{INTRODUCTION}

Data Envelopment Analysis (DEA) is a nonparametric mathematical tool for assessing the relative efficiency of homogeneous Decision Making Units (DMU). DEA has been applied in many sectors (education, health care, finance, utilities and so on. Traditional studies in DEA view systems as a whole when measuring the efficiency, ignoring the operation of individual processes within a system. In reality, Conventional DEA models consider the system as a single-process black box, that is, the units under assessment as a single process and assume that this aggregate process consumes all the different inputs and produces all the different outputs.

There are however a number of so-called network DEA approach that consider the system as composed by distinct processes or stages, each one with its own inputs and outputs and with intermediate flows among the stages. The Network DEA (NDEA) model was introduced by Fare and Grosskopf (2000) and Chen et al. (2010). Then Lewis and Sexton (2004) proposed a multi-stage structure for NDEA. Tone and Tsutsui (2009) proposed a slack based network DEA model, called Network SBM, which could deal with intermediate products formally. Also Kao (2009), in order to investigation network model, consider two parallel and series structure for internal parts of DMU. In this study, we consider a relational network DEA model, taking into account the interrelationship of the processes within the system, to measure the efficiency of the system and those of the processes at the same time. The system efficiency thus measured more properly represents the aggregate performance of the component processes. In this case, that considers the system as the composition of several stages or process that can have a series structure or that are executed in parallel or that have a more general interrelationships pattern. The common feature of all these approaches is that they work at a more fine-grained level so that each process has its own inputs and its own outputs and there may be intermediate flows among the processes.

\section{MATERIALS AND METHODS}

Systems with more than one process connected with each other are networks. To measure the efficiency of a network system a network DEA model is needed. Different from the conventional DEA model, the network DEA model does not have a standard form. It

Corresponding Author: Mohammad Mahallati Rayeni, Department of Management, Institute Technology of Bahonar, Zahedan, Iran 
depends on the structure of the network in question. Fare and Grosskopf (2000) and Fare et al. (2007) developed several network models that can be used to discuss variations of the standard DEA model. There are two basic structures for a network system, series and parallel. For each of the two structures, the system efficiency (or inefficiency) can be decomposed into efficiencies (or inefficiencies) of the component processes. Each is briefly described below.

Series structure: For a system consisting of two processes connected in series, Seiford and Zhu (1999) applied the conventional DEA model to calculate the efficiency of each process independently. Kao (2009) developed a relational model to calculate the efficiency of the system taking into account the series relationship of the two processes. An interesting result of the relational model is that the system efficiency is the product of the two process efficiencies. Their conclusion can be extended to general series systems of more than two processes. Note that a series model may be solved using backward induction.

Consider a series system of $\mathrm{h}$ processes. Let $\mathrm{x}_{\mathrm{ij}}$ and $\mathrm{y}_{\mathrm{rj}}$ be defined as the inputs and outputs of the system, respectively. Denote $\mathrm{z}_{\mathrm{pj}}^{\mathrm{k}}$ as the pth intermediate product, $\mathrm{p}=1, \ldots, \mathrm{q}$, of process $\mathrm{k}, \mathrm{k}=1, \ldots, \mathrm{h}-1$, for $\mathrm{DMU}_{\mathrm{j}}$. The intermediate products of process $k$ are the outputs of process $k$ as well as the inputs of process $k+1$. Note that the intermediate products of the last process $h$ are the outputs of the system. The number of intermediate products, q, can be different for each process. Here, it is assumed that they are the same for all processes just for simplification of notation. Mathematically, the system efficiency will be low if there is a process which is very inefficient and will be high only when all processes have high efficiencies.

Parallel structure: For a system composed of $h$ processes connected in parallel, Kao (2009) developed a DEA model to calculate the efficiency of the system. Let $x_{i j}^{k}$ be the ith input and $y_{\mathrm{rj}}^{k}$ the rth output of process $t$ for DMU $\mathrm{j}$. The sum of the ith input for all processes is equal to the ith input of the system of a DMU, i.e., $\sum_{\mathrm{k}=1}^{\mathrm{h}} \mathrm{x}_{\mathrm{ij}}^{\mathrm{k}}=\mathrm{x}_{\mathrm{ij}}$. This also applies to outputs; that is, $\sum_{\mathrm{k}=1}^{\mathrm{h}} \mathrm{y}_{\mathrm{rj}}^{\mathrm{k}}=\mathrm{y}_{\mathrm{rj}}$.

When the operations of all processes are taken into account, the system efficiency of $\mathrm{DMU}_{\mathrm{o}}$ is calculated from the following relational model:

$$
\begin{aligned}
& \theta=\text { Maximize : } \sum_{\mathrm{r}=1}^{\mathrm{s}} \mathrm{u}_{\mathrm{r}} \mathrm{y}_{\mathrm{ro}} \\
& \text { Subject to } \sum_{\mathrm{i}=1}^{\mathrm{m}} \mathrm{v}_{\mathrm{i}} \mathrm{x}_{\mathrm{io}}=1 \\
& \sum_{\mathrm{r}=1}^{\mathrm{s}} \mathrm{u}_{\mathrm{r}} \mathrm{y}_{\mathrm{rj}}-\sum_{\mathrm{i}=1}^{\mathrm{m}} \mathrm{v}_{\mathrm{i}} \mathrm{x}_{\mathrm{ij}} \leq 0 \mathrm{j}=1,2, \ldots, \mathrm{n} \\
& \sum_{\mathrm{r}=1}^{\mathrm{s}} \mathrm{u}_{\mathrm{r}} \mathrm{y}_{\mathrm{rj}}^{\mathrm{k}}-\sum_{\mathrm{i}=1}^{\mathrm{m}} \mathrm{v}_{\mathrm{i}} \mathrm{x}_{\mathrm{ij}}^{\mathrm{k}} \leq 0 \mathrm{k}=1,2, \ldots, \mathrm{h}, \mathrm{j}=1,2, \ldots, \mathrm{n}, \\
& \mathrm{u}_{\mathrm{r}} \geq \varepsilon \quad \mathrm{r}=1,2, \ldots, \mathrm{s}, \mathrm{v}_{\mathrm{i}} \geq \varepsilon \quad \mathrm{i}=1,2, \ldots, \mathrm{m}
\end{aligned}
$$

Similar to the case of the series structure, a parallel system is efficient only if all its component processes are efficient. The number of constraints for the parallel DEA model is also equal to the number of DMUs multiplied by the number of processes in the system.

\section{RESULTS}

Efficiency of the universities: Now, we consider the individual universities with their own departments. They consist of a finite set of sub-DMUs (departments) that are connected to form a parallel network. We apply the parallel network model. This network model enables us to study the processes that usually remain hidden within the "black box" of DEA.

Indicators (variables): The choice of indicators or in other words, effective factors on efficiency assessment in a university has great importance, because to succeed in performance assessment, precise choice and suitable one in selecting important factors and comparable in units under consideration should be carried out. The definition of indicators which show produced output in one educational unit or inputs to be viewed are not simple due to numerous effective factors. The effective input and output variables on educational department's efficiency were chosen after consultation with the management. The effective indicators on educational department's efficiency can be as the following: Input and output variables were chosen after consultation with the management. Input variables included the number of registered student $\left(\mathrm{x}_{1}\right)$, the number of teaching staff $\left(\mathrm{x}_{2}\right)$ and the number of presented unit by guest lecturers $\left(\mathrm{x}_{3}\right)$. Three output variables were selected to represent both teaching and research outcomes: the number of graduates $\left(\mathrm{y}_{1}\right)$, the number of passed students to higher levels $\left(\mathrm{y}_{2}\right)$ and the performed research work $\left(\mathrm{y}_{3}\right)$. 
Table 1: The gathered information of the universities in Sistan and Baluchestan state

\begin{tabular}{llrrrr}
\hline Academic year & Variables & \multicolumn{1}{c}{ S\&B } & Azad & Zabol & Payam \\
\hline $2003-2004$ & $\mathrm{X}_{1}$ & 9632 & 13495 & 6105 & 3830 \\
& $\mathrm{X}_{2}$ & 287 & 106 & 238 & 78 \\
& $\mathrm{X}_{3}$ & 202 & 1696 & 342 & 1144 \\
& $\mathrm{y}_{1}$ & 1884 & 1305 & 1906 & 1001 \\
& $\mathrm{y}_{2}$ & 355 & 53 & 246 & 190 \\
& $\mathrm{y}_{3}$ & 2939 & 835 & 1845 & 390 \\
& $\mathrm{x}_{1}$ & 14538 & 16104 & 10765 & 8586 \\
& $\mathrm{X}_{2}$ & 337 & 125 & 262 & 91 \\
& $\mathrm{X}_{3}$ & 221 & 1946 & 415 & 1411 \\
& $\mathrm{y}_{1}$ & 2368 & 1553 & 2360 & 1824 \\
& $\mathrm{y}_{2}$ & 375 & 61 & 264 & 213 \\
& $\mathrm{y}_{3}$ & 3655 & 815 & 2655 & 690 \\
\hline
\end{tabular}

Table 2: Technical efficiency of the universities

\begin{tabular}{llc}
\hline DMUs & $\begin{array}{c}\text { Efficiency in } \\
2003-2004\end{array}$ & $\begin{array}{c}\text { Efficiency in } \\
2008-2009\end{array}$ \\
\hline S\&B university & 0.675824 & 0.737023 \\
Azad university & 0.438092 & 0.479873 \\
Zabol university & 0.656303 & 0.864883 \\
Payam university & 0.809935 & 0.874027 \\
\hline
\end{tabular}

Efficiency of the universities: We consider each University is a DMU and each of their departments is sub-DMUs, which is a network in parallel system. Four universities under evaluation are S\&B University, Azad University, Zabol University, Payam University. The above mention universities have 82 departments. Table 1 provides a summary of the data, which was used as the basis of the analysis. The information was collected from different data files.

The network efficiency of the universities is computed using model (1). The results show in Table 2. We solved the models using LINDO software.

The average technical efficiency in academic year 2008-2009 increase about 15\%, in addition, the universities scores show an overall improvement.

\section{DISCUSSION}

Efficiency score dependence on inputs-outputs: The relative efficiency score achieved by each DMU, can be sensitive to the number of inputs and outputs specified. Moreover, there isn't a conventional method for choosing one DEA to report in preference to any other. In any application of DEA, it is therefore important, to test the sensitive of the results to changes in inputoutput specification.

In this case, we have defined seven DEA models with the referred above indicators. The seven models are constructed similarly, but differ only in one input or one output. The next table shows the different combinations of input-output, for each one of the proposed DEA models (Table 3 ).
As we can observe, the Model I contains one variable more than the other models. Accordingly the properties of DEA analysis, the scores achieved by the departments in the first model will be at least equal than the scores in the rest of the models. This way, checking the changes in the results of efficiency when is eliminated a variable. We can identify the strength of the universities with regard to the missing performance dimensions. If a university is not considered efficient in only one model, for example, this implies that the DMU bases its efficiency primarily on the variable which is omitted by the present model. On the other hand, when a department attains an efficient score in the seven evaluations, this suggests that this department is operating satisfactorily in terms of all activities.

Efficiency score dependence on inputs-outputs in academic year 2003-2004: First we investigate depending on efficiency scores and the choice of input and output variables in academic year 2003-2004.

Table 4 shows the scores of technical efficiency obtained by the Universities analyzed in each one of the models. The aim of measuring the level of efficiency using technical efficiency is that each University is compared with those that have similar characteristics.

According to the results of Table 4 in the Model I, which includes all variable discussed, efficiency of Payam is greater than all other DMUs.

We compute the correlation between the efficiencies of the units in the six compromised models with the Model I where all six variables are included. In Table 4, we see these correlations vary between 0.1829 (Scientific board omitted) to 0.9999 (Number of presented unit by guest lecturers omitted). This implies that the impact of omitting the scientific board in the study has the maximum impact on the computation of efficiencies. The Universities efficiency in the Model III is decreased. This fact reveals that the key factor of their efficiency is the indicator "Scientific board" that is missed in the Model III, while the impact of omitting Number of presented unit by guest lecturers has the minimal impact on the efficiency computations.

Payam University has averagely the most efficiency and its efficiency depend on the scientific board indicator, the presence of this variable result decisive in its assessment, which suffers a significance drop when it is not included. The research and the Number of presented unit by contracted or guest lecturers indicators is not considered in evaluation of its efficiency (the weightings of two indicators is considered zero in evaluating efficiency of this DMU). S\&B University attain the most efficiency in three Models II, III and V. 


\begin{tabular}{|c|c|c|c|c|c|c|c|}
\hline & Model I & Model II & Model III & Model IV & Model V & Model VI & Model VII \\
\hline $\mathrm{x}_{1}$ & $x$ & - & $x$ & $x$ & $x$ & $\times$ & $x$ \\
\hline $\mathrm{x}_{2}$ & $x$ & $x$ & - & $x$ & $x$ & $x$ & $x$ \\
\hline$x_{3}$ & $x$ & $x$ & $x$ & - & $x$ & $x$ & $x$ \\
\hline $\mathrm{y}_{1}$ & $x$ & $x$ & $x$ & $x$ & - & $x$ & $x$ \\
\hline $\mathrm{y}_{2}$ & $x$ & $x$ & $x$ & $x$ & $x$ & - & $x$ \\
\hline$y_{3}$ & $\times$ & $x$ & $x$ & $x$ & $x$ & $\times$ & - \\
\hline
\end{tabular}

Table 4: Score of technical efficiency of DMUs in academic year 2003-2004

\begin{tabular}{llllllll}
\hline & Model I & Model II & Model III & Model IV & Model V & Model VI & Model VII \\
\hline S\&B & 0.6758 & 0.6363 & 0.2576 & 0.6549 & 0.6758 & 0.5977 & 0.6518 \\
Azad & 0.4381 & 0.3914 & 0.0249 & 0.3773 & 0.2272 & 0.4381 & 0.4254 \\
Zabol & 0.6563 & 0.5346 & 0.1644 & 0.6323 & 0.5714 & 0.6563 & 0.6373 \\
Payam & 0.8099 & 0.6005 & 0.0296 & 0.8099 & 0.6692 & 0.6302 & 0.7984 \\
Correlation with Model I & 1.0000 & 0.8741 & 0.1829 & 0.9999 & 0.9283 & 0.8632 & 0.9993 \\
\hline
\end{tabular}

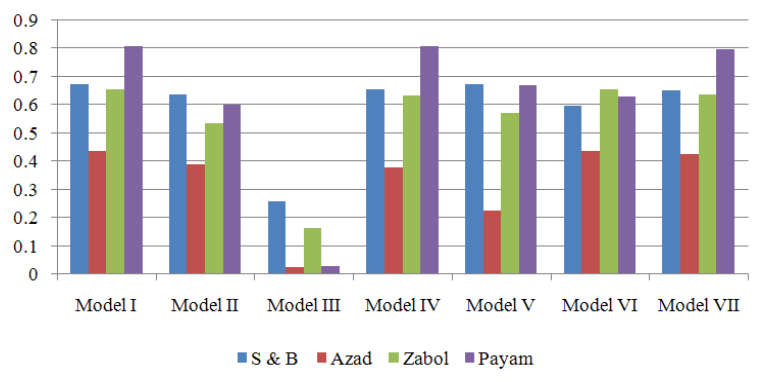

Fig. 1: The efficiency scores of the universities in seven models, academic year 2003-2004

Also it is almost stable in all models such as has the least standard deviation among DMUs, which indicate all indicators are effective in its efficiency score. Zabol University is the most efficiency in Model VI and weight of second output indicator is zero, therefore this indicator isn't effective on the performance this University. Azad University is the most inefficient in all models; this suggests that this university is operating unsatisfactorily in terms of all indicators. For better comparison of results of the models, Fig. 1 is plotted.

Efficiency score dependence on inputs-outputs in academic year 2008-2009: Now we investigate seven models in Table 3 for academic year 2008-2009 and the results of the models are indicated in Table 5.

As we can observe, the results of academic year 2008-2009 show depending the universities efficiency decrease scientific board (in contrast of academic year 2003-2004) and almost the universities efficiency is more stability relevant to academic year 2003-2004.

The most efficiency DMUs between models is Payam University that its average efficiency is equal 0.8060 . Second ranking is relevant to Zabol University; its average efficiency is equal 0.799. S\&B University has average efficiency 0.712 with standard deviation 0.033, which is minimum standard deviation. Azad University has the least efficiency.

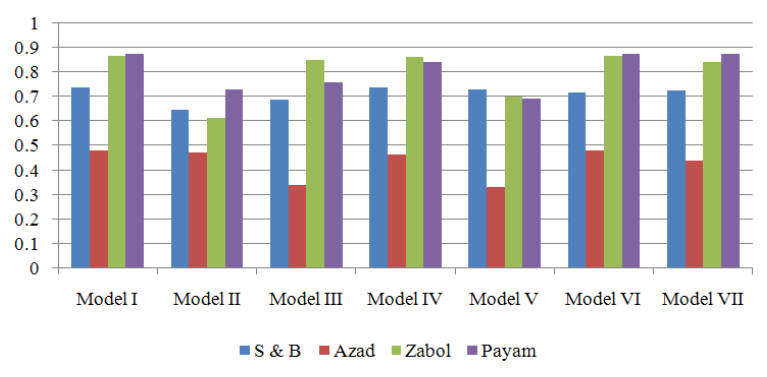

Fig. 2: The efficiency scores of the universities in seven models, academic year 2008-2009

The last row of Table 5 shows the correlation between the efficiencies of the units in the models with the Model I in academic year 2008-2009. We see these correlations vary between 0.8815 (Student admission omitted) to 0.9986 (Research omitted), which their changing range decrease relative to ago period. Therefore dependence on the all variables is almost equal. Though, in this academic year, the student admission variable has the maximum impact on the efficiency of the universities while the research has the minimal impact on the efficiency computations.

Figure 2 indicate efficiencies of DMUs in different models, also shows the impact almost same of variables.

The mean of efficiencies increase $31 \%$ in this period, also decrease the standard deviation, which indicate an overall improvement. In order to investigate precisely, in the later part, we calculate and analyze the productivity changes.

Malmquist productivity change indices: The Malmquist index approach to productivity measurement has many advantages. It is an index representing Total Factor Productivity (TFP) growth of a Decision Making Unit (DMU), in that it reflects (1) progress or regress in efficiency along with (2) progress or regress of the frontier technology between two periods of time. 
J. Computer Sci., 6 (11): 1252-1257, 2010

Table 5: Score of technical efficiency of DMUs in academic year 2008-2009

\begin{tabular}{llllllll}
\hline & Model I & Model II & Model III & Model IV & Model V & Model VI & Model VII \\
\hline S\&B & 0.7370 & 0.6466 & 0.6881 & 0.7370 & 0.7300 & 0.7165 & 0.7256 \\
Azad & 0.4799 & 0.4711 & 0.3366 & 0.4631 & 0.3290 & 0.4799 & 0.4390 \\
Zabol & 0.8649 & 0.6124 & 0.8515 & 0.8616 & 0.6982 & 0.8649 & 0.8412 \\
Payam & 0.8740 & 0.7302 & 0.7587 & 0.8403 & 0.6913 & 0.8738 & 0.8739 \\
Correlation with Model I & 1.0000 & 0.8815 & 0.9776 & 0.9965 & 0.9065 & 0.9985 & 0.9986 \\
\hline
\end{tabular}

Table 6: Malmquist productivity of DMUs

\begin{tabular}{llllllll}
\hline & $\theta^{\mathrm{t}}\left(\mathrm{x}^{\mathrm{s}}, \mathrm{y}^{\mathrm{s}}\right)$ & $\theta^{\mathrm{s}}\left(\mathrm{x}^{\mathrm{t}}, \mathrm{y}^{\mathrm{t}}\right)$ & TEC & $\frac{\theta^{\mathrm{t}}\left(\mathrm{x}^{\mathrm{s}}, \mathrm{y}^{\mathrm{s}}\right)}{\theta^{\mathrm{s}}\left(\mathrm{x}^{\mathrm{s}}, \mathrm{y}^{\mathrm{s}}\right)}$ & $\frac{\theta^{\mathrm{t}}\left(\mathrm{x}^{\mathrm{t}}, \mathrm{y}^{\mathrm{t}}\right)}{\theta^{\mathrm{s}}\left(\mathrm{x}^{\mathrm{t}}, \mathrm{y}^{\mathrm{t}}\right)}$ & FS & MI \\
\hline S\&B & 0.718 & 0.884 & 1.090 & 0.974 & 0.764 & 0.882 & 0.893 \\
Azad & 0.435 & 0.496 & 1.095 & 0.906 & 0.547 & 0.852 & 0.971 \\
Zabol & 1.147 & 1.199 & 1.318 & 1.327 & 0.899 & 0.930 & 1.123 \\
Payam & 0.841 & 0.901 & 1.079 & 0.962 & 1.004 \\
\hline
\end{tabular}

It is based on multi input-output frontier representations of the production technology (Cooper et al., 2006). In the empirical context, the results are obtained using mathematical programming techniques (DEA) that rely on minimum assumptions regarding the shape of the production frontier. Finally, the index decomposes into multiple components to give insights into the root sources of productivity change. DEA-based Malmquist productivity index measures the technical and productivity changes over time. The Malmquist Index (MI) is computed as the product of "Technical Efficiency Change (TEC)" and "Frontier Shift (FS)".

The technical efficiency change term relates to the degree to which a DMU improves or worsens its efficiency, while the frontier-shift term reflects the change in the efficient frontiers between the two time periods.

In order to assess productivity change over time in the Universities, we calculate Malmquist indices using DEA. We calculate the productivity change indices for two academic years 2003-2004 and 2008-2009. In Table 6, academic years 2003-2004 and 2008-2009 are called " $\mathrm{t}$ " and " $\mathrm{s}$ ", hence, $\left(\mathrm{x}^{\mathrm{t}}, \mathrm{y}^{\mathrm{t}}\right)$ and $\left(\mathrm{x}^{\mathrm{s}}, \mathrm{y}^{\mathrm{s}}\right)$ are inputs and outputs of DMUs in academic years 2003-2004 and 2008-2009, respectively.

So:

$$
\mathrm{TEC}=\frac{\theta^{\mathrm{s}}\left(\mathrm{x}^{\mathrm{s}}, \mathrm{y}^{\mathrm{s}}\right)}{\theta^{\mathrm{t}}\left(\mathrm{x}^{\mathrm{t}}, \mathrm{y}^{\mathrm{t}}\right)}
$$

and:

$$
\mathrm{FS}=\left[\frac{\theta^{\mathrm{t}}\left(\mathrm{x}^{\mathrm{s}}, \mathrm{y}^{\mathrm{s}}\right)}{\theta^{\mathrm{s}}\left(\mathrm{x}^{\mathrm{s}}, \mathrm{y}^{\mathrm{s}}\right)} \frac{\theta^{\mathrm{t}}\left(\mathrm{x}^{\mathrm{t}}, \mathrm{y}^{\mathrm{t}}\right)}{\theta^{\mathrm{s}}\left(\mathrm{x}^{\mathrm{t}}, \mathrm{y}^{\mathrm{t}}\right)}\right]^{\frac{1}{2}}
$$

Productivity changes and Malmquist productivity index are as Table 6.
We first look at the technical efficiency changes. Table 3 and 6 report the DEA technical efficiency and the associated the technical efficiency changes from 2004-2009. All DMUs have improving technical efficiency. The average technical efficiency of the universities is improved $14.57 \%$.

We next look at the frontier shift. The column 7 in

Table 6 reports the Malmquist frontier shift component, FS. It can be seen that on average, the frontier shift declined 11.6\% from 2004-2009 (because of the average frontier shift is 0.8839). As indicated by FS, all the universities show a negative shift in technology frontier. The columns' 5 and 6 of Table 6 reports the component shifts in technology frontier based. We see that from 2004-2009, the Universities technology frontier has a pure negative shift.

Technology change at the DMU level shows, for example, the two ratios associated with the frontier change index are smaller than 1 for S\&B, Azad and Payam Universities, indicating that these stays with a consistent operations strategy. Zabol University shows a move between two facets, indicating that this university has a change in operations strategy and moves from a negative shift facet towards a positive shift facet, indicating a favorable strategy change.

We finally look at the Malmquist productivity index. The column 8 of Table 6 reports Malmquist productivity index, MI. It can be seen that from academic year 2003-2004 to 2008-2009, the above mention universities experienced on average $1.1 \%$, productivity gain.

The university average productivity gain shown in Table 6 is a combined effect of an average improvement in Technical Efficiency Change (TEC) shown in column 4 of Table 6 and an average negative shift in technology frontier shown in column 7 in Table 6. Therefore, an improvement in technical efficiency is the only source of productivity gain. 


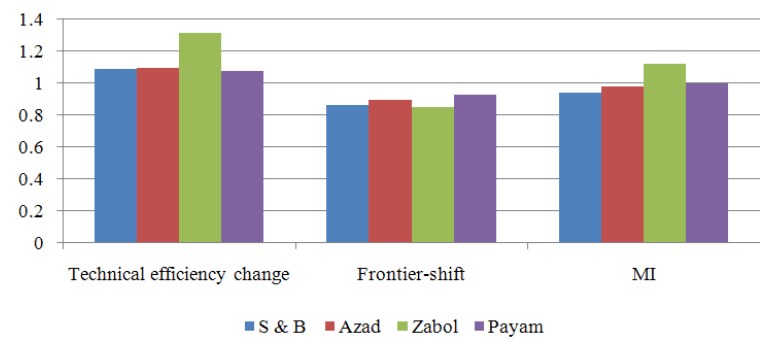

Fig. 3: The productivity changes and their decomposition

Now, we investigate the component information associated with the productivity change in each the universities. As shown in the Table 6, two Universities (S\&B and Azad) exhibit regress in total productivity index for the period under study, S\&B and Azad have regress 5.9 and $2 \%$, respectively.

The results show that Zabol university has productivity gain since its MI is greater of 1 (MI>1). In this University, the Malmquist productivity gain is from not only an efficiency improvement, but also a technology movement from negative shift section to positive shift section of the frontier, indicating that this University has a favorable strategy shift and also gains relative efficiency with respect to a positively shift frontier.

Although the activity of Payam University is associated with a negative technology shift but progress in technical efficiency is present, indicating that Payam in academic year 2008-2009 is closer to the frontier in academic year 2008-2009 than Payam in academic year 2003-2004 is, the negative frontier shift cannot absorb the improvement in technical efficiency, Payam has a slightly improvement in the productivity. Figure 3 shows the productivity changes using Malmquist indexes and relevant components including technical efficiency change and frontier shift for individual universities.

The models are implemented in an MS-Excel worksheet and are solved by using the DEA Solver software and LINDO software.

\section{CONCLUSION}

In this study we consider the problem of estimating efficiency and productivity for universities. We have examined performance evaluation concepts of universities using a parallel structure network DEA approach. The efficiency scores and Malmquist index components are more valid, because of network DEA allows for a more fine-grained analysis that leads to a more realistic estimation of the overall system production possibility set than the one assumed by conventional DEA. In addition, the calculated efficiency in two time periods, we investigate the impact of each variable on the efficiency scores in two periods.

The average Malmquist index indicates a general productivity increase in the period 2004-2009. The increasing productivity is because of progress in technical efficiency change, also frontier shift declined 11.6\% from 2004-2009 and also only one DMU indicates a favorable strategy change.

\section{REFERENCES}

Chen, T.H., C.P. Bao, C.M. Huang and I.C. Wang, 2010. Efficiency decomposition with enhancing russell measure in data envelopment analysis. Am. J. Applied Sci., 7: 438-441. http://www.scipub.org/fulltext/ajas/ajas73438-441.pdf

Cooper, W.W., L.M. Seiford and K. Tone, 2006. Data Envelopment Analysis: A Comprehensive Text with Models, Applications, References and DEASolver Software. 2nd Edn., Springer, Boston, ISBN: 10: 0387452818, pp: 490.

Fare, R. and S. Grosskopf, 2000. Network DEA. Soc.Econ. Plann. Sci., 34: 35-49. DOI: 10.1016/S00380121(99)00012-9

Fare, R., S. Grosskopf and G. Whittaker, 2007. Network DEA. In: Modeling Data Irregularities and Structural Complexities in DEA, Zhu, J. and W.D. Cook (Eds.). Springer, New York, ISBN: 10: 0387716068, pp: 209-240.

Kao, C., 2009. Efficiency decomposition in network data envelopment analysis: A relational model. Eur. J. Operat. Res., 192: 949-962. DOI: 10.1016/j.ejor.2007.10.008

Lewis, H.F. and T.R. Sexton, 2004. Network DEA: efficiency analysis of organizations with, complex internal structure. Comput. Operat. Res., 31: 1365-1410. DOI: $10.1016 / \mathrm{S} 0305-0548(03) 00095-9$

Seiford, L.M. and J. Zhu, 1999. Profitability and marketability of the top 55 U.S. commercial banks. Manage. Sci., 45: 1270-1288. DOI: 10.1287/mnsc.45.9.1270

Tone, K. and M. Tsutsui, 2009. Network DEA: A slacks-based measure approach. Eur. J. Operat. Res., $\quad$ 197: 243-252. DOI: 10.1016/j.ejor.2008.05.027 